OPEN ACCESS

Edited by:

Constance Finney,

University of Calgary, Canada

Reviewed by:

Irah L. King,

McGill University, Canada

Henry J. McSorley,

University of Dundee, United Kingdom

Simon Babayan,

University of Glasgow,

United Kingdom

*Correspondence:

Laura Cervi

laura.cervi@unc.edu.ar

Specialty section:

This article was submitted to

Microbial Immunology,

a section of the journal

Frontiers in Immunology

Received: 07 April 2020

Accepted: 31 July 2020

Published: 20 October 2020

Citation:

Silvane L, Celias DP, Romagnoli PA, Maletto $B A$, Sanchez Vallecillo MF,

Chiapello LS, Palma SD,

Allemandi DA, Sanabria REF,

Pruzzo Cl, Motrán CC and Cervi L

(2020) A Vaccine Based on

Kunitz-Type Molecule Confers

Protection Against Fasciola hepatica

Challenge by Inducing IFN- $\gamma$ and

Antibody Immune Responses Through

IL-17A Production.

Front. Immunol. 11:2087.

doi: 10.3389/fimmu.2020.02087

\section{A Vaccine Based on Kunitz-Type Molecule Confers Protection Against Fasciola hepatica Challenge by Inducing IFN $-\gamma$ and Antibody Immune Responses Through IL-17A Production}

Leonardo Silvane 1,2, Daiana Pamela Celias 1,2, Pablo Alberto Romagnoli, Belkys Angélica Maletto 1,2, María Fernanda Sanchez Vallecillo ${ }^{1,2}$, Laura Silvina Chiapello ${ }^{1,2}$, Santiago Daniel Palma ${ }^{5,6}$, Daniel Alberto Allemandi5,6, Rodrigo Eduardo Fabrizio Sanabriaa,8, César Iván Pruzzo ${ }^{7}$, Claudia Cristina Motrán ${ }^{1,2}$ and Laura Cervi ${ }^{1,2 *}$

\footnotetext{
${ }^{1}$ Departamento de Bioquímica Clínica, Facultad de Ciencias Químicas, Universidad Nacional de Córdoba, Córdoba, Argentina, ${ }^{2}$ Centro de investigaciones en Bioquímica Clínica e Inmunología (CIBICI), Consejo Nacional de Investigaciones Cientificas y Técnicas (CONICET), Córdoba, Argentina, ${ }^{3}$ Centro de Investigación en Medicina Traslacional Severo Amuchastegui (CIMETSA), Córdoba, Argentina, ${ }^{4}$ Instituto Universitario de Ciencias Biomédicas de Córdoba (IUCBC), Consejo Nacional de Investigaciones Científicas y Técnicas (CONICET), Córdoba, Argentina, ${ }^{5}$ Departamento de Farmacia, Facultad de Ciencias Químicas, Universidad Nacional de Córdoba, Córdoba, Argentina, ${ }^{6}$ Unidad de Investigación y desarrollo en Tecnología Farmacéutica (UNITEFA), Consejo Nacional de Investigaciones Científicas y Técnicas (CONICET), Córdoba, Argentina, ${ }^{7}$ Facultad de Ciencias Veterinarias, Universidad Nacional de La Plata, La Plata, Argentina, ${ }^{8}$ Instituto Tecnológico Chascomús (INTECH), Consejo Nacional de Investigaciones Científicas y Técnicas, Universidad Nacional de San Martín (CONICET/UNSAM), Chascomús, Argentina
}

Fasciola hepatica is helminth parasite found around the world that causes fasciolosis, a chronic disease affecting mainly cattle, sheep, and occasionally humans. Triclabendazole is the drug of choice to treat this parasite. However, the continuous use of this drug has led to the development of parasite resistance and, consequently, the limitation of its effectiveness. Hence, vaccination appears as an attractive option to develop. In this work, we evaluated the potential of F. hepatica Kunitz-type molecule (FhKTM) as an antigen formulated with a liquid crystal nanostructure formed by self-assembly of 6-O-ascorbyl palmitate ester (Coa-ASC16) and the synthetic oligodeoxynucleotide containing unmethylated cytosine-guanine motifs (CpG-ODN) during an experimental model of fasciolosis in mice, and we further dissected the immune response associated with host protection. Our results showed that immunization of mice with FhKTM/CpG-ODN/Coa-ASC16 induces protection against $F$. hepatica challenge by preventing liver damage and improving survival after $F$. hepatica infection. FhKTM/CpG-ODN/Coa-ASC16-immunized mice elicited potent IFN- $\gamma$ and IL-17A with high levels of antigen-specific IgG1, IgG2a, and IgA serum antibodies. Strikingly, IL-17A blockade during infection decreased IgG2a and IgA antibody levels as well as IFN- $\gamma$ production, leading to an increase in mortality of vaccinated mice. The present study 
highlights the potential of a new vaccine formulation to improve control and help the eradication of $F$. hepatica infection, with potential applications for natural hosts such as cattle and sheep.

Keywords: Th17-dependent protection, nanostructure, ascorbyl palmitate, kunitz type molecule, vaccine, Fasciola hepatica

\section{INTRODUCTION}

Fasciolosis is a zoonotic and chronic disease caused by a helminth parasite, F. hepatica, that causes huge economic losses in animal production worldwide. These losses have been estimated to be US\$ 3 billion due to a reduction in milk, wool, and meat production in cows and sheep $(1,2)$. On the other hand, the World Health Organization (WHO) has reported that approximately 2.4 million people are infected by this parasite worldwide. Fasciolosis has recently been declared as an emerging disease in humans with an increased number of cases in some regions of the planet (3). The frontline drug against fasciolosis is triclabendazole. However, the emergence of resistance to this drug in diverse $F$. hepatica populations $(4,5)$, and its high cost suggest the need for other control strategies. In this sense, developing a vaccine against this parasite would be a better preventive control strategy. Moreover, vaccines are considered safe and environmentally friendly because their use ensures the absence of chemical residues in food, as well as in pasture (1).

Both cattle and humans are infected by the ingestion of metacercariae, the infective stage, encysted in aquatic plants. After that, the newly excysted juveniles (NEJ) fluke emerges in the intestine and penetrates the intestinal wall in its migration through the peritoneum and liver parenchyma to finally allocate in the bile ducts.

During its migration, the parasite releases an array of molecules from its intestinal content called excretory-secretory products (FhES) or its tegumental coat (FhTeg), which are the main source of immune-modulatory molecules (6-8).

These complex parasite-derived molecules can interact with the immune system and inhibit the Th1-driven protective pro-inflammatory responses through the induction of M2 macrophages (9), mast cells (10), and Th2-type responses (11, $12)$, and promote regulatory $\mathrm{T}$ (Treg) cell development $(6,13)$. Thus, the induction of an ineffective immune response against this parasite allows the development of a chronic infection.

Over the last 25 years, there have been numerous attempts to formulate a successful vaccine against $F$. hepatica by using parasite extracts or individual antigens (14, 15). These formulations achieved different levels of protection in experimental models of mice, rats, sheep, and cattle $(1,16,17)$ by the induction of an antibody response and/or Th1/Th17-mediated cellular immunity (18-22).

However, a commercially viable vaccine against $F$. hepatica with an appropriate level of efficacy is not available yet.

Among the molecules released by the parasite, the most abundant are proteases and protease inhibitors $(14,23,24)$. The proteases secreted by $F$. hepatica allow its migration through the tissues and modulate the immune system, which enables its establishment and permanence in the host. However, a tight control of this enzymatic activity should be regulated by protease inhibitors. Kunitz type molecule (FhKTM) is a member of the inhibitory protease family expressed in the FhES and FhTeg during the juvenile stage, suggesting an essential role in controlling proteolytic activity (25). Thus, the physiological function of FhKTM may be to protect the parasite from the host and parasite proteases by inhibiting its activity. In our study we tested a FhKTM peptide as a vaccine antigen.

On the other hand, new approaches have focused on the design of innovative methods to improve immune response involving mainly suitable adjuvant strategies (26). Over the last decade, an area of extreme development has been the application of nanomaterials to vaccine development. In this line, the adjuvant capacity of the synthetic oligodeoxynucleotide containing unmethylated cytosine-guanine motifs (CpGODN) (agonist of TLR9) formulated with liquid crystal-type nanostructures formed by self-assembly from ascorbyl 6-Opalmitate ester (Coa-ASC16) has been demonstrated. The immunization of mice with the ovalbumin (OVA) protein, together with the adjuvant CpG-ODN/Coa-ASC16, induced a potent antigen-specific antibodies and Th1/Th17/CD8 + T-cell cellular responses without toxic systemic effects $(27,28)$.

In this work, we evaluated the potential of an FhKTM peptide formulated in a nanostructure based on CpG-ODN/Coa-ASC16 as a vaccine during an experimental model of fasciolosis in mice and we further dissected the immune response associated with host protection.

\section{MATERIALS AND METHODS}

\section{Animals}

Wild-type 8- to 10-week-old female BALB/c mice were obtained from the Faculty of Veterinary Sciences, National University of Litoral (UNL, Argentina) and housed in the Animal Facility of the Faculty of Chemical Sciences, National University of Córdoba.

\section{Ethics Statement}

All animal experiments were approved by and conducted in accordance with the guidelines of the committee for Animal Care and Use of the Faculty of Chemical Sciences, National University of Córdoba (Approval Number HCD 881) in strict accordance with the recommendation of the Guide to the Care and Use of Experimental Animals published by the Canadian Council on Animal Care (OLAW Assurance number A5802-01).

\section{Antigens and Adjuvant}

A FhKTM peptide according to the sequence described by Bozas et al. (29) was synthesized by ONTORES 
TABLE 1 | Processing mice in each group.

\begin{tabular}{ll}
\hline Groups & Treatments \\
\hline Untreated & Non-immunized and uninfected \\
Infected & Non-immunized and infected \\
CpG-ODN/Coa-ASC16 & Immunized with adjuvant and infected \\
FhKTM/CpG- & Immunized with \\
ODN/Coa-ASC16 & FhKTM/CpG-ODN/Coa-ASC16 and \\
& infected
\end{tabular}

Biotechnologies (Zhejiang, China). The identity and purity of the peptide was analyzed by analytical reversed-phase high-performance liquid chromatography (RP-HPLC) and mass spectrometry MALDI-TOF (purity >95\%). Class-B CpG-ODN 1826 (5'-TCCATGACGTTCCTGACGTT-3') with total phosphorothioate-modification was provided by Operon Technologies, Alameda, CA, United States. To prepare CoaASC16-based formulations, FhKTM peptide and/or CpG-ODN were added to a dispersion of $2 \%(\mathrm{w} / \mathrm{v})$ ASC16 in 5\% dextrose solution, heated up to $72^{\circ} \mathrm{C}$ for $15 \mathrm{~min}$, and then allowed to reach room temperature as described previously (27).

\section{Vaccination With FhKTM/CpG-ODN/Coa-ASC16}

$\mathrm{BALB} / \mathrm{c}$ mice were randomly divided into four groups $(n=$ 4-5) as described in Table 1. Immunizations were performed three times at one-week intervals over 2 weeks. Each mouse was subcutaneously immunized with an entire dose $(250 \mu \mathrm{l})$ equally distributed at five sites: tail, back, neck region, and both hind limbs $(50 \mu \mathrm{l} /$ site). CpG-ODN was administered at $75 \mu \mathrm{g} /$ mouse/dose. The FhKTM dose was $10 \mu \mathrm{g} / \mathrm{mouse} / \mathrm{dose}$. One week after the last immunization, all groups were orally infected with 6 metacercariae of F. hepatica (Sanabria Laboratory, Universidad Nacional de la Plata, La Plata, Argentina). Mice were sacrificed at three different days, 0, 4, and 24, after infection.

\section{Cytokine Detection Assay}

Peyer patches (PPs) were harvested from the small intestine of mice and then incubated in RPMI 1640 medium (Gibco BRL, Life Technologies, Grand Island, NY) containing $0.5 \mathrm{mg} / \mathrm{ml}$ collagenase, $2 \%(\mathrm{~V} / \mathrm{V})$ fetal bovine serum (FBS; Thermo Fisher Scientific), $100 \mathrm{U} / \mathrm{ml}$ penicillin, and $100 \mu \mathrm{g} / \mathrm{ml}$ streptomycin for $30 \mathrm{~min}$. The PPs cells were filtered through a cell strainer $(100 \mu \mathrm{m} ; \mathrm{BD})$ and washed with the medium without collagenase. The cells were suspended in RPMI 1640 medium containing $10 \%(\mathrm{~V} / \mathrm{V}) \mathrm{FBS}, 55 \mu \mathrm{M}$ 2-mercaptoethanol, $100 \mathrm{U} / \mathrm{ml}$ penicillin, and $100 \mu \mathrm{g} / \mathrm{ml}$ streptomycin and then cultured at $1.0 \times 10^{5}$ cells/well in a U-bottom 96-well plate stimulated with FhKTM ( $2 \mu \mathrm{g} /$ well) for 3 days at $37^{\circ} \mathrm{C}$ under $5 \%$ of $\mathrm{CO}_{2}$ and $95 \%$ air. Spleen, mesenteric lymph nodes (MLNs), and inguinal lymph node (ILNs) cells were obtained, homogenized, and suspended in RPMI 1640 medium (Gibco BRL, Life Technologies, Grand Island, NY) supplemented with 10\% FCS (Gibco), $1 \mathrm{mM}$ sodiumpyruvate, $2 \mathrm{mM}$ l-glutamine, $100 \mathrm{U}$ of penicillin/ml, and $100 \mu \mathrm{g} / \mathrm{ml}$ of streptomycin (complete medium). Cultures were incubated at $37^{\circ} \mathrm{C}$ in a humidified atmosphere $\left(5 \% \mathrm{CO}_{2}\right)$ and stimulated with FhKTM $(2 \mu \mathrm{g} / \mathrm{ml})$ for $72 \mathrm{~h}$. At the end of the incubations, cell culture supernatants were collected, aliquoted, and frozen at $-80^{\circ} \mathrm{C}$ until being analyzed for IFN- $\gamma$, IL17A, IL-4, IL-5, and IL-10 by sandwich ELISA according to the manufacturer's guidelines (BD Pharmingen, San Jose, CA, United States).

\section{Treatment With $\alpha$ IL-17A Antibody}

Monoclonal antibody was applied to the vaccinated group to induce the functional inhibition of IL-17A. Two days before and after infection, FhKTM/CpG-ODN/Coa-ASC16 vaccinated and infected mice were injected with $250 \mu \mathrm{g}$ (100 $\mu l$ i.p./mouse/dose) of $\alpha$ IL-17A antibody (Invitrogen, Thermo Fisher Scientific, Waltham, MA, United States). The FhKTM/CpG-ODN/Coa-ASC16 and infected groups were alternatively injected with the non-specific isotype control IgG (Invitrogen, Thermo Fisher Scientific, Waltham, MA, United States) (100 $\mu$ l i.p./mouse/dose) (30).

\section{Survival Curves}

Mortality and survival of mice in different groups were observed until the completion of the experiment and survival curves were plotted until day 75 post-infection by using GraphPad Prism 6.01 software (GraphPad Software, San Diego, CA).

\section{Liver Analysis}

The analysis of livers consisted of two parts. Gross lesions were scored (range 0 to 5) according to the method described by Changklungmoa $\mathrm{N}$ et al. (31) taking into account the extension of damage on the surface of livers. The histopathological examination was done after livers were fixed in $10 \%$ neutralbuffered formalin for $48 \mathrm{~h}$, followed by paraffin embedding. Sections of $5 \mu \mathrm{m}$ were stained with hematoxylin and eosin (HE). Histological samples were scored according to Chien-Chang Chen et al. (32) with modifications. The lesions were scored between 0 and 9 based on the following findings: infiltration of inflammatory cells (score range, 0 to 3 ), together with the evaluation of liver tissue damage (necrosis, hemorrhagic foci, fibrosis, score range 0 to 3 ), and presence of tunnels and flukes (score range, 0 to 3 ), with 0 as normal and 9 as the most diseased.

\section{Antigen Specific Antibody Titers}

FhKTM-specific titers of IgA in fecal extracts and IgG isotypes (IgG1 and IgG2a) in serum were determined by ELISA. Fecal extracts were prepared by suspending five fecal pellets in $0.5 \mathrm{ml}$ of extraction buffer $(100 \mu \mathrm{g} / \mathrm{ml}$ soybean trypsin inhibitor, Sigma Aldrich St. Louis, MO, United States), $10 \mathrm{mg} / \mathrm{ml}$ bovine serum albumin (Sigma Aldrich, St.Louis, MO, United States), and $30 \mathrm{mM}$ disodium EDTA in PBS ( $\mathrm{pH}=7.6)$. After homogenization and centrifugation at $4^{\circ} \mathrm{C}$, the supernatants of the fecal extracts were used for IgA determination in feces (33). Blood was allowed to clot, and serum was removed and stored at $-20^{\circ} \mathrm{C}$ until use. The small intestinal contents were flushed out with $3 \mathrm{~mL}$ of PBS. The intestinal lavage fluids were centrifuged at 9,200 $\mathrm{g}$ for $5 \mathrm{~min}$ at $4^{\circ} \mathrm{C}$ and the supernatants were stored at $-80^{\circ} \mathrm{C}$ until analysis. For ELISA, FhKTM was diluted at $10 \mu \mathrm{g} / \mathrm{ml}$ in 
A

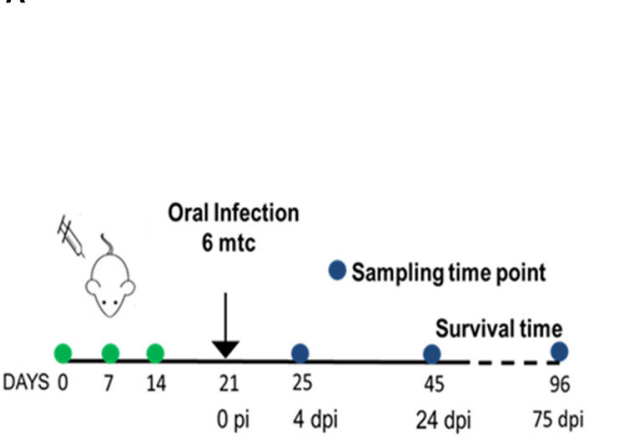

B

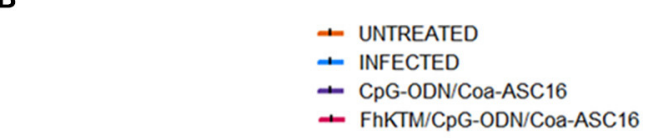

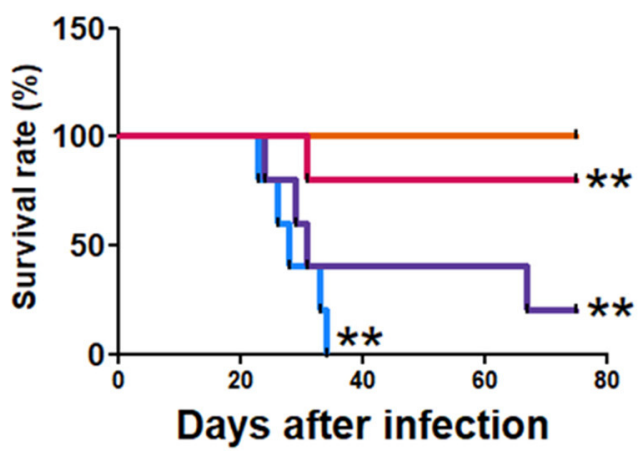

FIGURE 1 | Vaccination with FhKTM/CpG-ODN/Coa-ASC16 increases the survival rate in F. hepatica infected mice. (A) Scheme of the vaccination and challenge experiments. BALB/c mice were injected s.c. in the upper and dorsal region on days 0, 7, and 14 with FhKTM/CpG-ODN/Coa-ASC16, CpG-ODN/Coa-ASC16, or PBS (infected). One week later, the mice were oral-challenged with 6 metacercariae of $F$. hepatica. Non-vaccinated non-infected (untreated) mice were used as a negative control group. The samples were obtained at 4 and 24 dpi. (B) Survival was monitored for $>75$ days. Each group comprised of five mice. Survival was significantly higher in the FhKTM/CpG-ODN/Coa-ASC16-immunized mice than in the control groups. Kaplan-Meier curves were generated and survival was compared across groups using the log-rank test ${ }^{\star \star} p<0.05$. This figure is representative of two experiments with similar results.

$\mathrm{NaHCO} 31 \mathrm{M}(\mathrm{pH}=9.6)$, and ELISA plates were coated in 100 $\mu \mathrm{l} /$ well overnight at $4^{\circ} \mathrm{C}$. Plates were blocked with $5 \%$ bovine serum albumin (BSA) in $\mathrm{PBS}$ at $37^{\circ} \mathrm{C}$ for $1 \mathrm{~h}$ and washed with PBS-Tween $0.05 \%$. Samples were incubated for $2 \mathrm{~h}$ at room temperature and after washing, rat anti-mouse IgA-HRP (BD Pharmingen, San Jose, CA, United States) or anti-mouse IgG-HRP (Invitrogen, Thermo Fisher Scientific, Waltham, MA, United States) diluted in 1\% PBS-BSA were added for $1 \mathrm{~h}$ at room temperature. Finally, detection was performed with BD Opt EIA ${ }^{\mathrm{TM}}$ TMB Substrate Reagent Set (BD, San Diego, CA, United States). Titers were calculated as the reciprocal of the last serum dilution that yielded an absorbance at $490 \mathrm{~nm}$ above that of twice the mean value of blank. The sera from the non-immunized group (untreated) were represented by a full line.

\section{ALT and AST Measurement}

The serum concentrations of alanine aminotransferase (ALT) and aspartate aminotransferase (AST) were determined using a kinetic-UV method by BIOCON laboratory, Cordoba, Argentina, under the established manufacturer's protocols.

\section{Statistical Analysis}

Data were analyzed using GraphPad Prism 6.01 software (GraphPad Software, SanDiego, CA). Data analysis included one-way ANOVA followed by a Tukey's post-test for multiple comparisons and the unpaired Student's $t$-test. In survival experiments, Kaplan-Meier curves were analyzed with log-rank test. All data were considered statistically significant for $p$-values of $*<0.05, * *<0.01$ or $* * *<0.001$ depending on the experiment.

\section{RESULTS}

\section{FhKTM/CpG-ODN/Coa-ASC16 Vaccination Protects Against $F$. hepatica Infection}

To study whether FhKTM/CpG-ODN/Coa-ASC16 protects against $F$. hepatica infection, we followed an experimental procedure of immunization and infection described in Figure 1A. Samples from mice were obtained on days 25 and 45 after the first immunization (Figure 1A). In addition, the survival rates of infected mice were evaluated until 75 days post infection (dpi). Figure 1B shows that all infected mice died by day 32 pi, while immunization with FhKTM/CpGODN/Coa-ASC16 effectively increased mice survival, showing no significant differences with untreated animals. Moreover, mice injected only with CpG-ODN/Coa-ASC16 showed a survival impairment, with their survival significantly lower than it was observed for FhKTM/CpG-ODN/Coa-ASC16-vaccinated mice (Figure 1B). Taking into account that vaccination with FhKTM/CpG-ODN/Coa-ASC16 prolonged infected mice survival, we investigated the level of damage in the liver, the target organ of infection, establishing a macroscopical score (range 0 to 5 ) according to the extension of surface liver lesions. The infected and CpG-ODN/Coa-ASC16-injected mice showed significantly higher scores of liver lesions than the FhKTM/CpG-ODN/Coa-ASC16 vaccinated group, which did not present damage in the liver (Figure 2A). All vaccinated mice exhibited a microscopically preserved liver architecture comparable to the untreated group (Figure 2B). In contrast, livers from both infected and CpG-ODN/Coa-ASC16-injected mice presented migratory tunnels $(\mathrm{T})$ containing young flukes (thin arrows), large areas of fibrosis that replace hepatic parenchyma (thick arrows), and large leukocyte infiltrates 
A

\section{UNTREATED INFECTED}
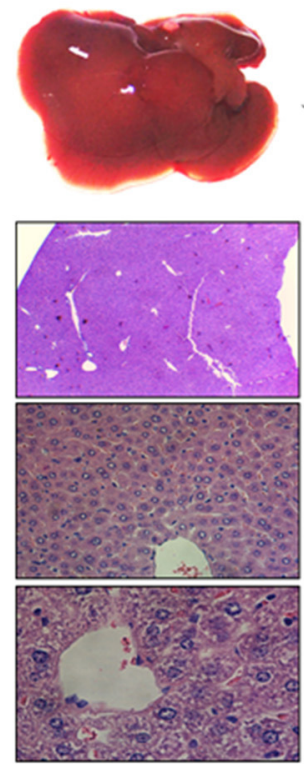
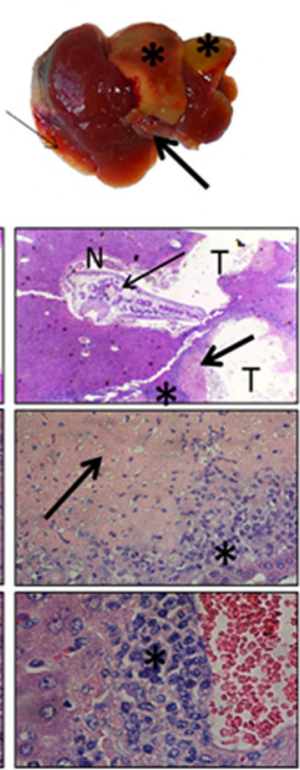

\section{CpG-ODN} ICoa-ASC16
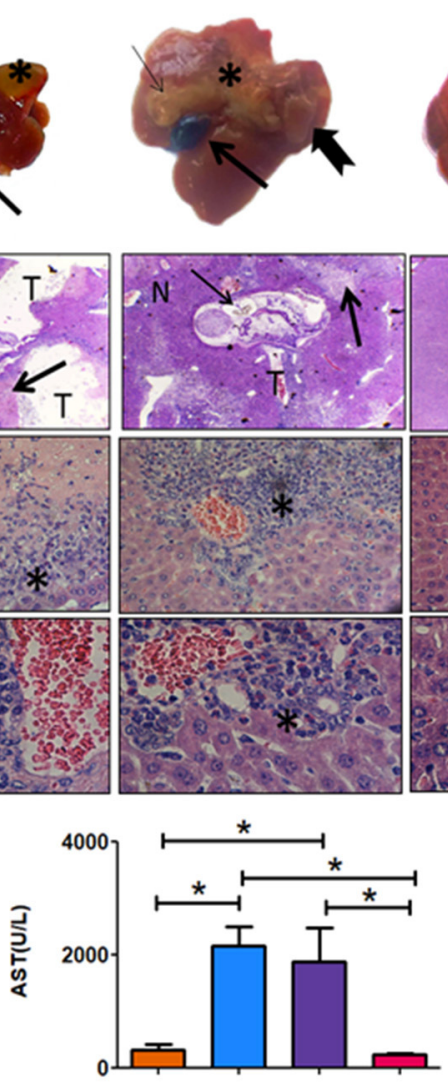

FhKTM/CpG-ODN ICoa-ASC16
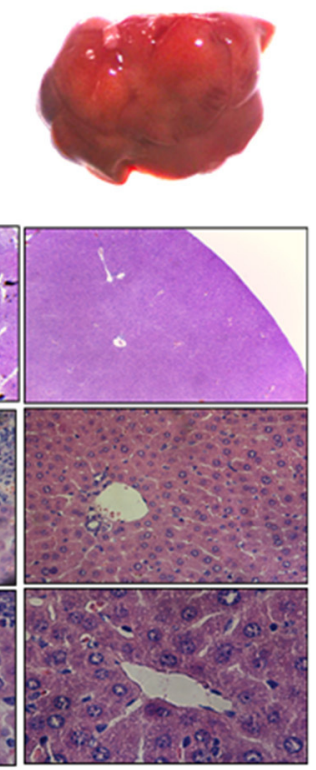

$\square$ UNTREATED

$\square$ INFECTED

$\square \mathrm{CpG}-\mathrm{ODN} / \mathrm{Coa}-\mathrm{ASC} 16$

$\square$ FhKTM/CPG-ODN/Coa-ASC16

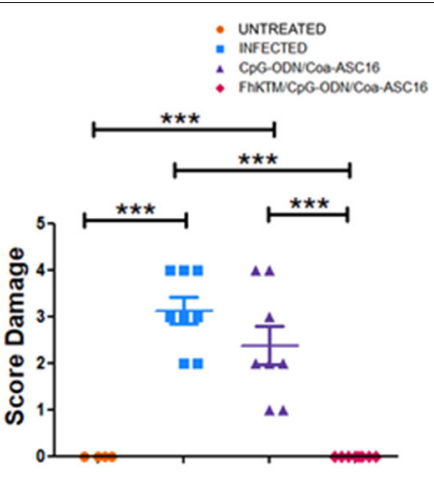

C

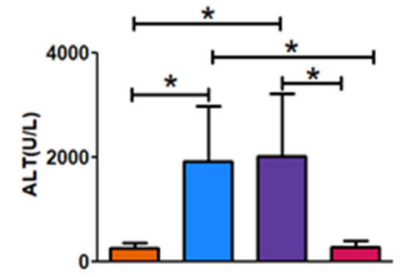

FIGURE 2 | FhKTM/CpG-ODN/Coa-ASC16 immunization in mice prevented liver damage caused by F. hepatica infection. Gross lesions of livers from mice after 24 days of the infection with $F$. hepatica or without infection. (A) Untreated: tissue from mice without treatment showed a standard architecture with no observed lesions. Infected: there are marked irregularities of capsule (thin arrow), changes in the tissue color (asterix) belonging to the growing fibrosis generated, and enlargement of bile ducts (thick arrow). CpG-ODN/Coa-ASC16: multiple foci of fibrosis (asterix), also enlargement, thickening, and color changes due to hemorrhages in the gallbladder (thick arrow) and the presence of worms on the liver surface (notched arrow). FhKTM/CpG-ODN/Coa-ASC16: the livers maintained a structure similar to the untreated control mice without visible lesions. Right, the score was assessed by the extensión of liver damaged (score range 0 to 5). The data shown are pooled from two independent experiments with total ( $n=5-8$ per group). (B) Histopatological evaluation of livers from the different groups was performed 24 days after infection. Left, untreated control mice showed the expected mice hepatic architecture (left panel) [H/E, $100 \times$ (top) 400× (middle panel) $900 \times$ (below)]. The infected group exhibited migrating newly excysted juvenile fluke (NEJ) in the hepatic parenchyma (thin arrow), associated tract (T), extensive Inflammatory infiltrate $\left(^{*}\right)$, moderate hepatocyte necrosis (N), and fibrotic connective tissue proliferation (thick arrow) at the chronic stage of the infection (center left panel). Likewise,

CpG-ODN/Coa-ASC16 control evidenced the presence of NEJ and the consequences thereof (center right). FhKTM/CpG-ODN/Coa-ASC16 mice maintained the liver parenchyma structure despite infection (right panel). Right, histological samples were scored between 0 and 9 based on the following findings: infiltration of inflammatory cells (score range, 0 to 3), together with the evaluation of liver tissue damage (necrosis, haemorragic foci, fibrosis, score range 0 to 3 ), and the presence of tunnels and flukes (score range, 0 to 3), with 0 as normal and 9 as the most diseased. The data shown are pooled from two independent experiments with total ( $n$ = 5-8 per group). (C) Serum was collected at the time of euthanasia, 24 days after challenge. The levels of AST (right), aspartate aminotransferase; ALT (left), and alanine aminotransferase were determined by using a kinetic-UV method, under the established manufacturer's protocols. Data were analyzed by one-way ANOVA and Tukey's post-test ${ }^{\star} P<0.05 ;{ }^{* \star \star} P<0.001$. Data are shown as mean $\pm \mathrm{SD}$. All data are representative of two individual experiments.

(asterisk) (Figure 2B). Results showing the histopathological analysis of the livers are summarized in Figure 2B. Accordingly, FhKTM/CpG-ODN/Coa-ASC16-immunized mice showed serum ALT and AST levels similar to those observed in untreated animals (Figure 2C). As expected, ALT and AST levels were significantly increased in sera from infected and
CpG-ODN/Coa-ASC16-injected mice (Figure 2C). In summary, high survival rates and no significant changes in the liver structure, together with normal concentrations of hepatic enzymes (ALT and AST), demonstrate the effectiveness of the FhKTM/CpG-ODN/Coa-ASC16 vaccine to protect mice against F. hepatica infection. 


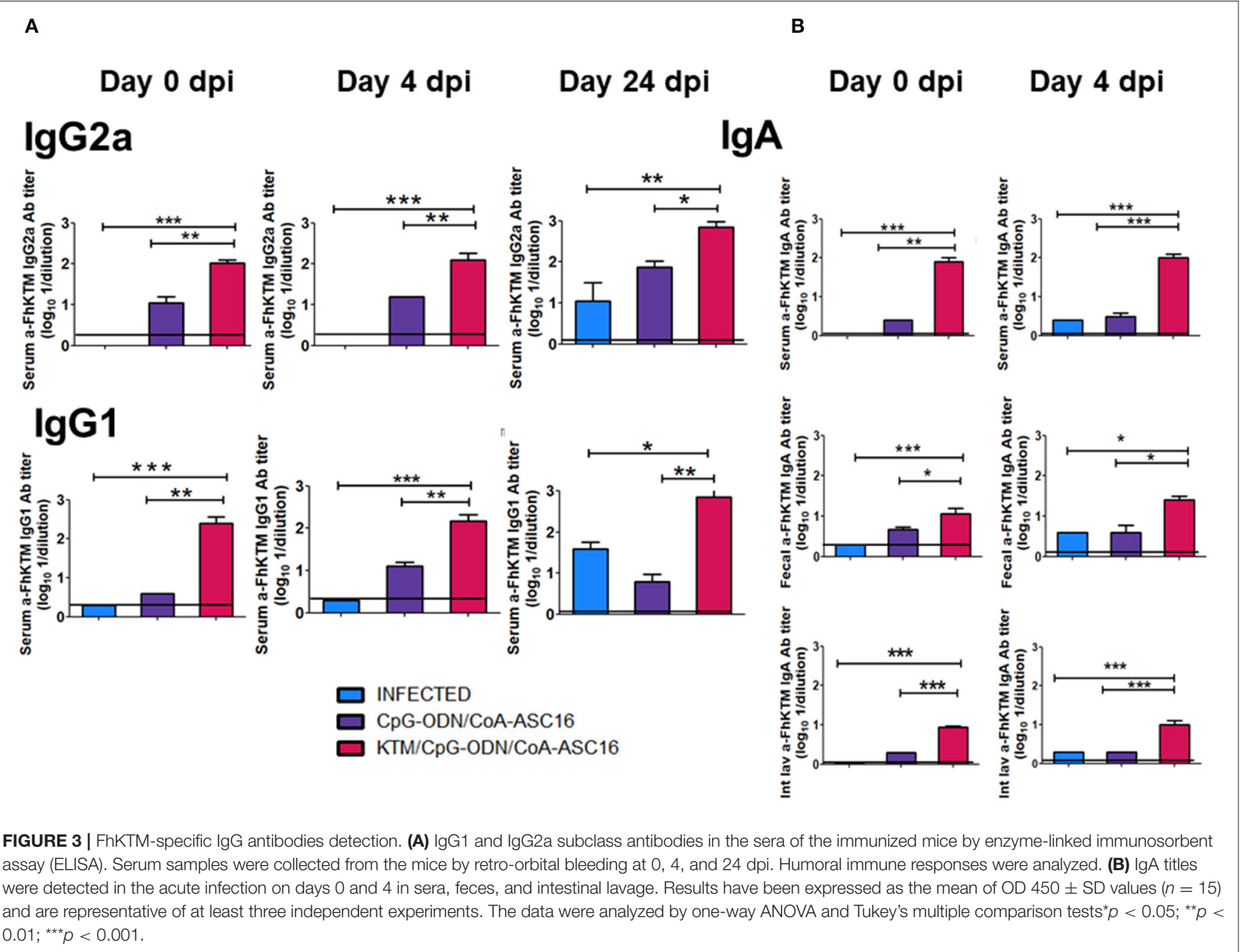

\section{FhKTM/CpG-ODN/Coa-ASC16 Immunization Elicits Strong \\ Antigen-Specific Humoral Immune Responses}

It has been reported that one important protective mechanism against $F$. hepatica is the humoral response $(14,18,34,35)$. Therefore, to evaluate whether FhKTM/CpG-ODN/CoaASC16 promotes an antigen-specific antibody response and primes the infection-induced humoral response, the levels of IgG1 and IgG2a antibodies against FhKTM were determined by ELISA in sera from FhKTM/CpG-ODN/Coa-ASC16immunized, infected, and CpG-ODN/Coa-ASC16-injected mice on 0 , 4, and $24 \mathrm{dpi}$. The anti-FhKTM IgG2a and IgG1 titers are depicted in Figure 3A, with the levels of anti-FhKTM obtained in untreated mice indicated as a line. Seven days after the third immunization (0 dpi, Figure 1A), FhKTM/CpGODN/Coa-ASC16-immunized mice showed significantly higher titers of FhKTM-specific IgG1 and IgG2a antibodies than CpG-ODN/Coa-ASC16-injected mice (Figure 3A). In addition, immunization worked as an effective stimulus for boosting the infection-induced antibody response, because at 4 and $24 \mathrm{dpi}$, FhKTM/CpG-ODN/Coa-ASC16-immunized mice showed significantly higher titers of IgG1 and IgG2a anti-FhKTM than those observed in serum from the other two infected experimental groups (infected and CpG-ODN/CoaASC16) (Figure 3A). Next, to evaluate the IgA immune responses induced by the vaccine formulation systemically and at a mucosal level, titers of FhKTM-specific IgA in serum, fecal pellets, and intestinal lavage were determined by ELISA (Figure 3B). According to what was observed in the systemic response for IgG1 and IgG2a, strong IgA responses were observed by vaccination with FhKTM/CpGODN/Coa-ASC16. Together, these data indicate that this vaccine is effective at inducing a specific antibody response at a systemic level and also in the intestine, with the latter being really important considering the migration period of the parasite through the host intestine wall at an early time after infection. 

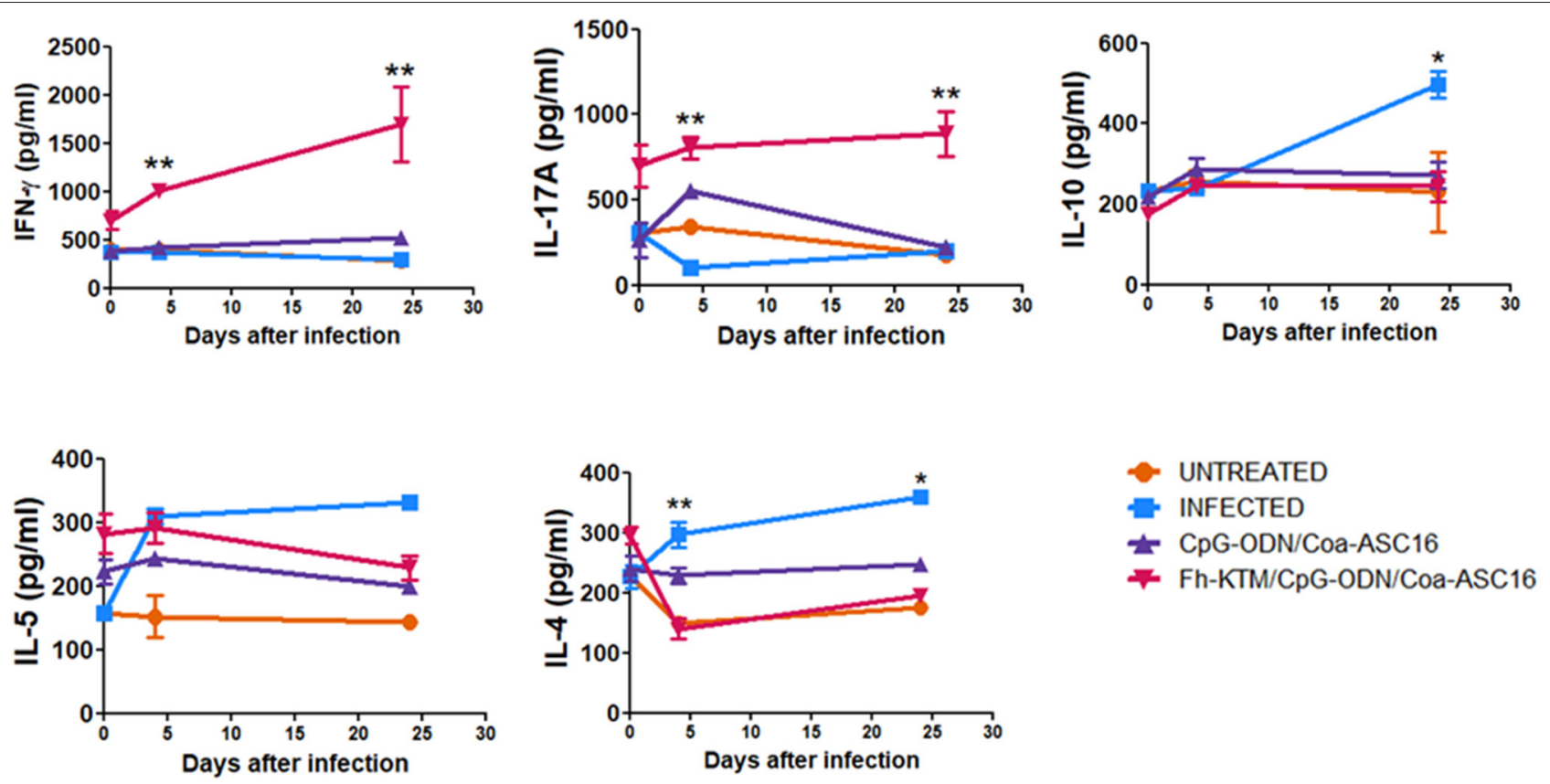

FIGURE 4 | FhKTM-specific cytokine immune responses in BALB/c mice after vaccination. At 0, 4, and 24 dpi, spleens were collected and splenocytes were stimulated in vitro with FhKTM for $72 \mathrm{~h}$. The culture supernatants from spleen cells were assessed for the production of IL-17A, IFN- $\gamma$, IL-10, IL-5, and IL-4 by ELISA. Results are shown as mean \pm SD and levels of significance as indicated by $p$-values and are representative of two or three independent experiments. They were assessed by one-way ANOVA and Tukey's multiple comparison tests ${ }^{*} p<0.05 ;{ }^{* *} p<0.01$.

\section{Immunization With}

\section{FhKTM/CpG-ODN/Coa-ASC16 Enhances Antigen-Specific IL-17A and IFN- $\gamma$ Production}

Next, we evaluated whether vaccination with FhKTM/CpGODN/Coa-ASC16 is also able to promote an antigen-specific cellular response. To this end, $\mathrm{BALB} / \mathrm{c}$ mice that were vaccinated and infected according to the scheme of Figure 1A were euthanized on 0,4 , and $24 \mathrm{dpi}$ and the capacity of splenocytes to produce IFN- $\gamma$, IL-17A, IL-10, IL-5, and IL-4 after restimulation with FhKTM was assessed in the culture supernatants by ELISA. As shown in Figure 4, vaccination with FhKTM/CpGODN/Coa-ASC16 was able to induce a strong cellular response characterized by enhanced secretion of IL-17A and IFN- $\gamma$, whereas only a weak production of IL-4 and IL-5 was observed, thereby suggesting the stimulation of dominant Th17 and Th1 responses. Moreover, the IL-17A and IFN- $\gamma$ production was markedly increased after the infection (Figure 4). As previously described (36), F. hepatica infection induces an increase in IL4-, IL-5-, and IL-10-producing splenocytes, while FhKTM/CpGODN/Coa-ASC16-immunized mice not only did not increase IL10- production but also decreased IL-4-producing splenocytes after the infection (Figure 4). Taking into account that an early IL-17A production has been previously demonstrated to promote IgA class switching in lymph organs (37), and considering our data showing increased IgA in feces as well as in intestinal lavage, we examined cytokine production by lymphatic organs for mucosal immunity, such as MLNs and PPs. Figure 5 shows that after three immunizations and prior to infection, MLNs or PP cells from FhKTM/CpG-ODN/Coa-ASC16-immunized mice produced high levels of IL-17A and IFN- $\gamma$ after antigen-specific stimulation. In addition, MLNs or PP cells from vaccinated mice secreted higher levels of these cytokines compared to those secreted by cells of MLNs or PP from CpG-ODN/Coa-ASC16 and infected mice (Figure 5).

These data suggest that IL-17A and IFN- $\gamma$ production could generate an inflammatory environment during the parasite migration which might contribute to its elimination.

\section{In vivo Neutralization of IL-17A Abolishes the Protective Capacity of FhKTM/CpG-ODN/Coa-ASC16 Vaccination}

IL-17 production has been associated with plasma cells switching to IgG2a antibodies and the promotion to IgA isotype (38, 39). In addition, IFN- $\gamma$ has been involved in the protection against $F$. hepatica $(19,20,40)$. Moreover IL-17A can act synergistically with IFN- $\gamma$ to activate antiparasitic mechanisms by macrophages (41). Taking into account these reports and our results showing high levels of IL-17A after vaccination, we decided to investigate the role of IL-17A on vaccineinduced protection. Groups of FhKTM/CpG-ODN/Coa-ASC16immunized or PBS-treated (infected) mice received neutralizing IL-17AmAb or isotype-matched control mAb 2 days before and after the oral challenge with the metacercariae (Figure 6A). Injection of neutralizing $\alpha$-IL-17A mAb, but not control $\mathrm{mAb}$, significantly decreased the serum levels of vaccine-induced IgG2a 


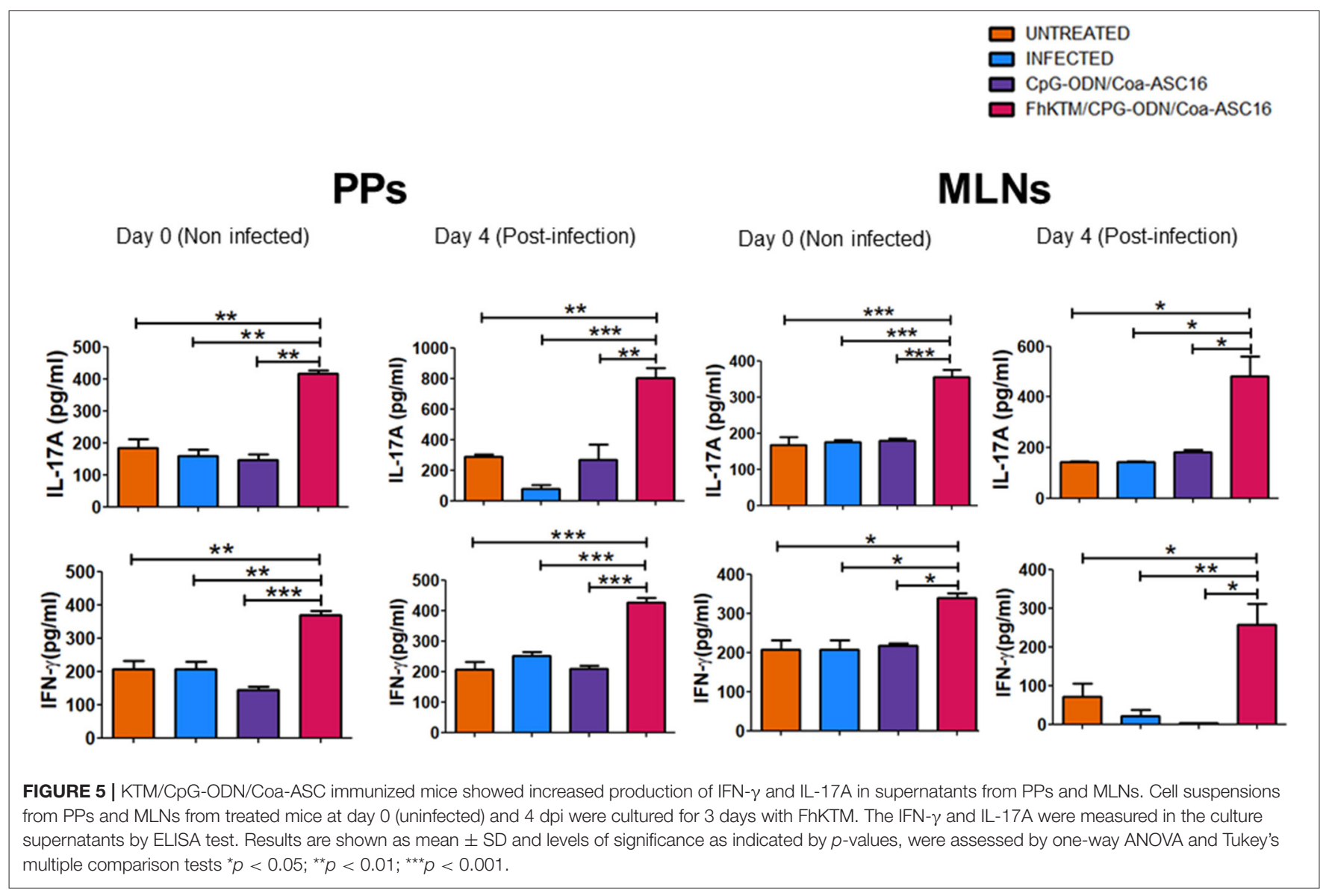

and $\operatorname{IgA}$ as well as fecal $\operatorname{IgA}$ titles, but did not significantly affect IgG1 production (Figure 6B). Likewise, splenocytes from vaccinated mice that were treated with $\alpha$-IL-17A mAb, but not control $\mathrm{mAb}$, showed diminished IFN- $\gamma$ production after antigen stimulation in culture (Figure 6C). In addition, the vaccine-induced protection appeared to be mediated by an IL-17A-driven immune response because treatment of mice with neutralizing $\alpha$-IL-17A mAb abolished the protective effect evaluated as survival rate (Figures 7A,B). Thus, FhKTM/CpGODN/Coa-ASC16-immunized mice and those treated with antiIL17A neutralizing antibody decreased their survival compared with vaccinated animals without treatment (lines violet vs. fucsia) (Figure 7B) and increased the gross liver damage (Figure 7C). Interestingly, the IL-17A neutralization decreased the survival of $F$. hepatica infected mice with or without treatment (lines pink and light blue), suggesting an important role of IL-17A in the protection against $F$. hepatica. These data highlight the remarkable role played by IL-17A as a regulator of IFN- $\gamma$ production and specific antibody response which correlates with the survival levels found in mice after the infectious challenge.

\section{DISCUSSION}

The production of an efficient vaccine against $F$. hepatica remains a major challenge for the scientific community for different reasons. The anti-helminthic resistance, high rates of reinfection in endemic areas, and the acute infection cases provoking animal death have raised the need for developing a vaccine against fasciolosis $(1,14)$. However, the most important challenge in vaccine design against this helminth is the possibility of beating the Th2-type or immunosuppressive responses with a view to an efficient response to eliminate the parasite. So far, numerous vaccination attempts have included different purified parasite molecules or their recombinant forms in cattle, sheep, and goats with varying levels of protection (14, 42-44).

To date, the vaccination trials developed against $F$. hepatica are not reproducible among animal models, in which variable levels of protection are achieved regardless if the antigen is native or recombinant. A number of antigens have been tested as promising vaccine candidates in mice $(22,45,46)$. However, partial protection, insufficient improvement in animal survival, or hepatic damage is not be enough to merit progress in the development of a commercially viable vaccine for livestock production. For these reasons, it is still important to define new vaccine candidates and efficient adjuvant formulations in murine models prior to the examination of the protective capacity in natural hosts such as cows or sheep.

The rationale for the vaccine design in this work was based on the properties of FhKTM. Apart from being an abundant protein within the parasite gut, the parenchymal tissue, and the tegument of juvenile (NEJ) (25) and adult (29), its role as protease inhibitor enables the parasite to avoid both its own and the 


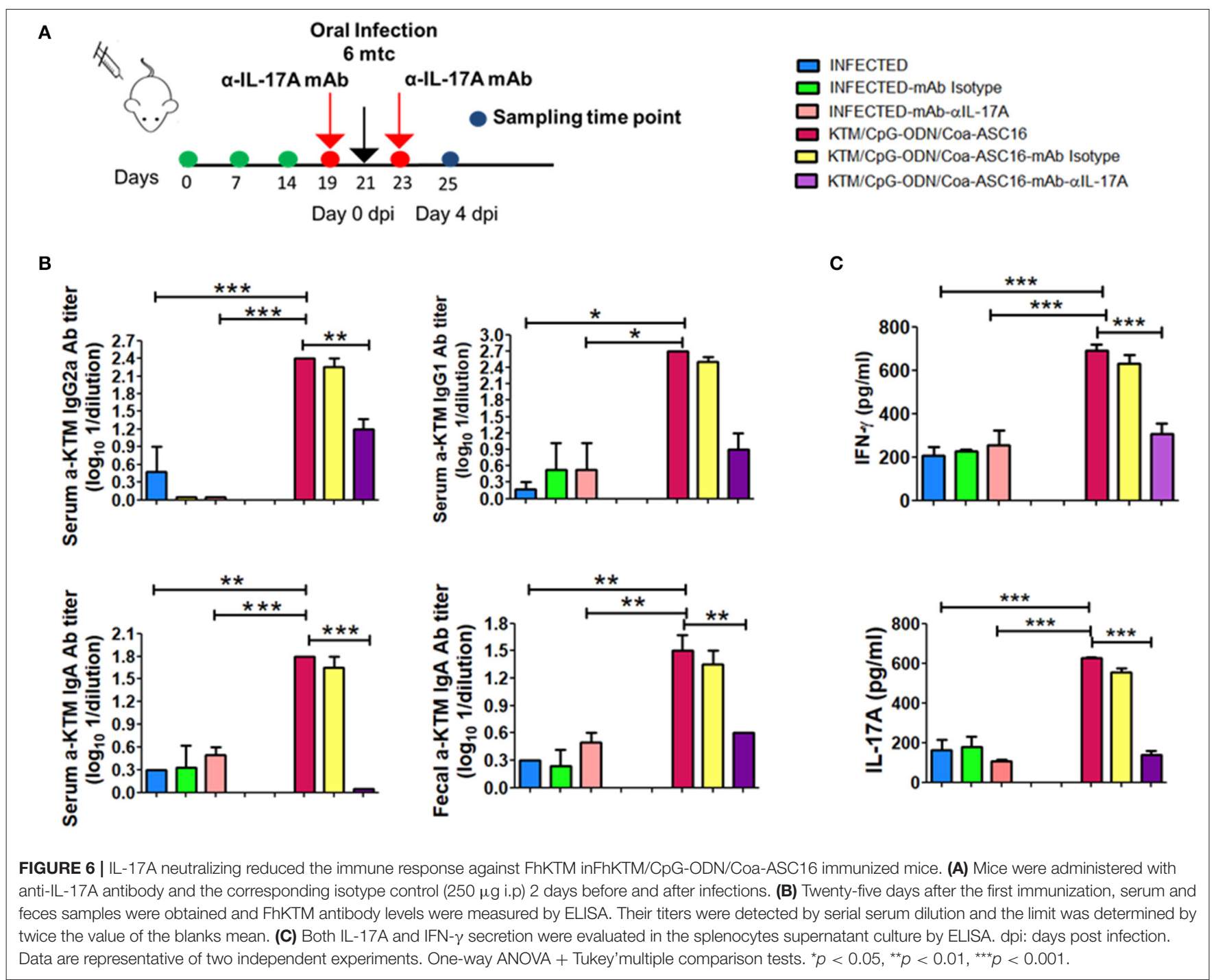

host's deleterious protease action. Along with this, the antigen was formulated with a novel adjuvant strategy, CpG-ODN/CoaASC16, that constitutes a nanoplatform. This adjuvant strategy is able to induce potent Th1 and Th17 responses, and elicit long-term antibody responses $(27,28)$. In this study we demonstrated that the immunization of mice with FhKTM/CpGODN/Coa-ASC16 increases the survival against $F$. hepatica challenge. Accordingly, the immunized animals presented a highly preserved liver structure, suggesting that mice vaccination somehow prevented worms from reaching the liver. This idea is also supported by results showing that immunization induces early production of specific antibodies and cytokines associated with INF- $\gamma$ and IL-I7 protection, both systemically and locally in MLNs and PPs after infection. On the one hand, high levels of FhKTM-specific IgA in the intestinal content as well as in feces from vaccinated mice could favor the hypothetical expulsion of parasites. Although F. hepatica is a trematode that remains for a short period of time in the intestine, the mechanisms of parasite expulsion in the gut as a result of vaccination could also be operating against the larval stage of this parasite. As described by others, the transference of IgA or IgG1 antibodies from resistant mice to helminth infections confers partial resistance to different nematodes $(47,48)$, probably through their neutralizing effect on secreted parasite antigens, or by trapping larvae (4951). In addition, we cannot not rule out the possibility that antibodies generated during immunization with the vaccine might participate in mechanisms of antibody-dependent cellmediated cytotoxicity (ADCC) and reactive oxygen and nitrogen species (ROS and NOS), according to results reported in in vitro studies by Piedrafita et al. (52). On the other hand, a critical role for IL-17A in the protective immunity against $F$. hepatica shown in this study is an interesting finding, whereas the Th1 profile has been the response mostly associated with protective mechanisms $(19,20,53)$. The fact that IL-17A was crucial to induce the IgA isotype in the fecal content of vaccinated mice correlates with the ability of Th17 cells shown by other authors to become precursors for the follicular helper T cells in PPs and to induce IgA class switching (54). This fact could be explained 
A

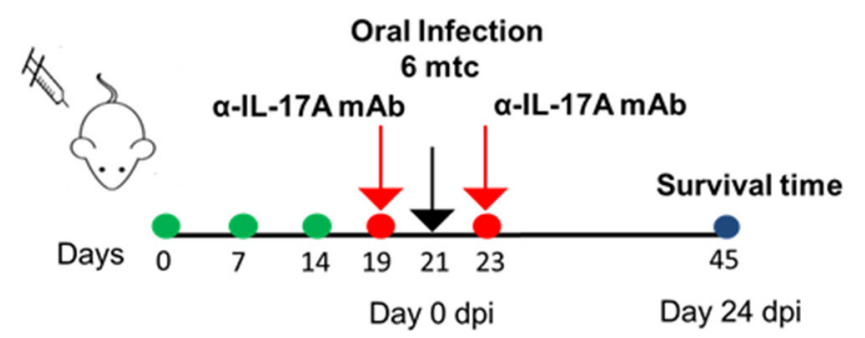

C

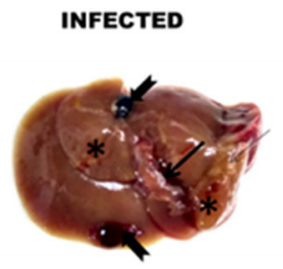

FhKTM/CpG-ODN/CoaASC16

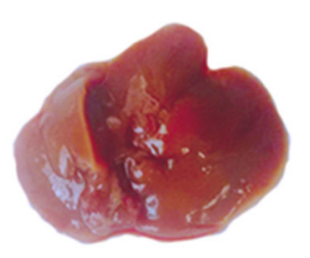

INFECTED-mAb-alL-17A

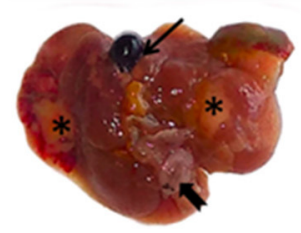

FhKTM/CpG-ODN/ CoaASC16 -mAb-all-17A

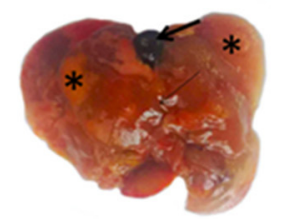

B

- UNTREATED

- INFECTED

- INFECTED-MAb Isotype

- FHKTMCDG-OONCCOa-ASC

- FHKTMMCDG-ODNCOa-ASC16

- FnKTMCPG-ODNCOa-ASC16-mab isotype

- FnKTINCDG-ODNCOa-ASC16-mAb-all-17A
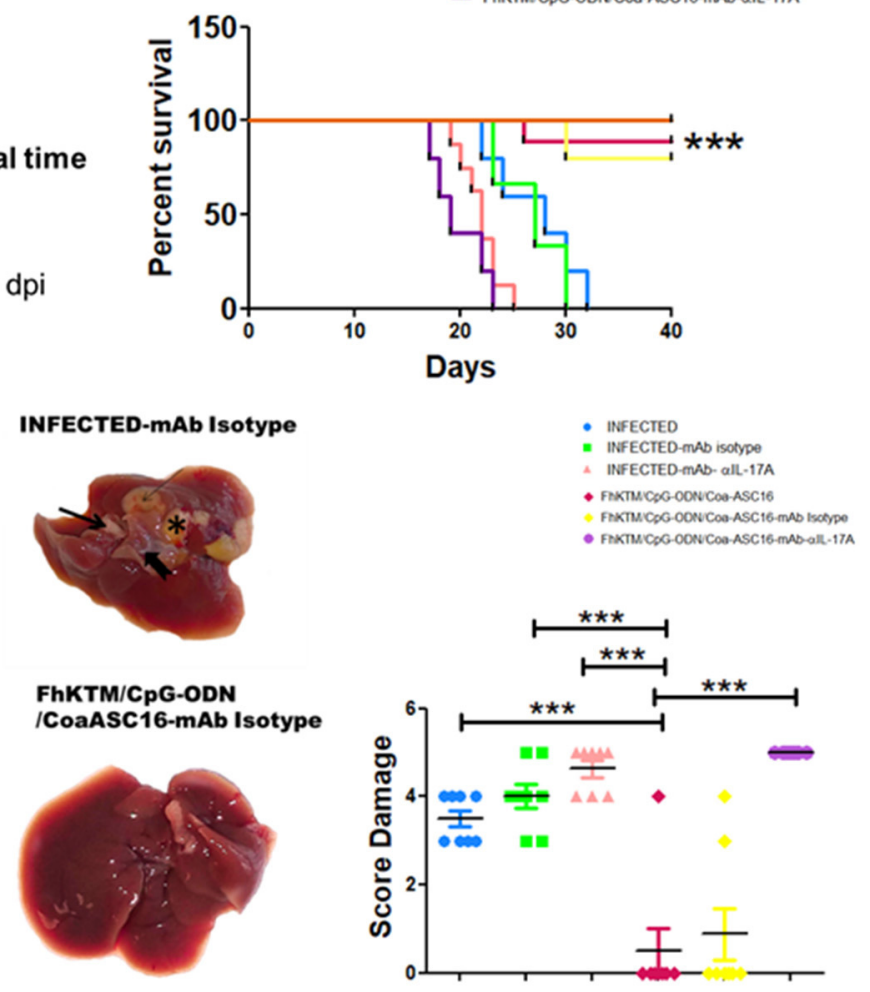

FIGURE 7 | IL-17A neutralization decreased the efficacy of FhKTM/CpG-ODN/Coa-ASC16 vaccination. (A) Mice were administered with anti-IL-17A antibody and the corresponding isotype control (250 $\mu \mathrm{g}$ i.p) 2 days before and after infections. (B) Kaplan-Meier graphs show survival curves for those mice immunized three times with FhKTM/CpG-ODN/Coa-ASC16 or PBS. IL-17A-mAb and corresponding isotype control (mAb Isotype) were administered 2 days both before and after infection. dpi: days post infection. (C) Left: infected liver showing marked enlargement with distended gallbladder (thick arrow), areas of fibrosis extending (asterix), and larvae on the parenchyma surface (notched arrow). FhKTM/CpG-ODN/Coa-ASC16: liver showing normal size with no observed lesion except in 1 out of 8 mice. Infected-mAb-IL-17A: the liver showing marked severe macroscopic damage (thin arrow) and presented irregular surface denoting hepatic fibrosis (asterix). The presence of larvae on the surface can be seen (notched arrow). FhKTM/CpG-ODN/Coa-ASC16 -mAb-IL-17A: The hepatic parenchyma is severely reduced, firm, and presents an irregular surface (thin arrow) denoting hepatic fibrosis (asterix). Abnormal gross appearance of the distended gallbladder with presence of blood inside (thick arrow). infected-mAb Isotype: the liver is smaller than normal and presents irregular surface tissue denoting hypertrophied (thin arrow) and replaced with fibrosis (asterix) and a fluke released after the rupture of the gallbladder (notched arrow). FhKTM/CpG-ODN/Coa-ASC16-mAb Isotype: liver showing no apparent gross pathology except for in 2 out of 8 mice. Right, the score damage was assessed by the extensión of liver damaged (score range 0 to 5). The data shown are pooled from two independent experiments with total $\left(n=5-8\right.$ per group). The statistical differences among survival curves were calculated by using Mantel-Cox test. ${ }^{\star \star \star} p<$ 0.001 .

by the capacity of IL-17A to increase the transport and secretion of IgA into the intestinal lumen (38). Moreover, Th17 celldeficient mice had an impaired antigen-specific intestinal IgA after immunization with cholera toxin, pointing out that Th17 cells were responsible for inducing the switch of GC B cells toward the production of high-affinity T cell-dependent IgA (54). Given the important role of IL-17 in the protective immunity induced by the vaccine, we cannot rule out the presence of innate as well as adaptive cells as a possible source of Th17, since both $\mathrm{CD}^{+}$and CD4 ${ }^{-}$IL17A-producing cells were found in the spleen of vaccinated animals (data not shown). Among the effector mechanisms of IL-17A there appears the ability to recruit neutrophils, which destroy the pathogen through the production of cytokines, chemokines, and anti-microbial peptides or myeloid cells which in turn restrict pathogen survival through activation and recruitment of Th1 cells (55). In the present study, a low neutrophil recruitment at the peritoneal cavity was observed in all experimental mice without significant differences among the groups (data not shown). On the other hand, the passage of worms through the intestinal wall that could induce neutrophil recruitment is random and transitory, so its finding might be difficult. The uncoupled IL-17A-dependent effector mechanisms from the neutrophil response have already been demonstrated in barrier tissues, in mouse models oropharyngeal, or skin fungal infections where IL-17A provided immunity through antimicrobial peptide generation (56), independently of neutrophils 
(57). These data suggest that the mechanism by which IL-17A plays a crucial role in the protective immunity against $F$. hepatica might be independent from neutrophil recruitment, and is still to be determined.

In addition, high systemic production of IFN- $\gamma$ and IgG2A levels in vaccinated animals is in agreement with previous reports showing the association of these responses with increased levels of protection against the parasite (34). A close relationship between IL-17A and IFN- $\gamma$ production was demonstrated in this work since the blockade of IL-17A significantly decreased IFN$\gamma$ levels in splenocyte supernatants and, consequently, animal survival. The precise mechanism by which the production of IFN- $\gamma$ is dependent on IL-17 is unknown, however, it could be speculated that after this cytokine is produced, responder cells such as epithelial or myeloid cells through IL17R signaling might induce the recruitment of Th1 cells. These cells could secrete pro-inflammatory cytokines, chemokines, and anti-microbial peptides to restrict the pathogenesis of the disease (55). Although these mechanisms have been proposed in different bacterial $(58,59)$ or protozoal infections $(60)$, we cannot rule out that IL-17A might play a similar role during F. hepatica infection.

Data from other authors support the idea of a synergistic effect between IFN- $\gamma$ and IL-17A in protective mechanisms against different pathogens through the potentiation of $\mathrm{NO}$ production in macrophages $(41,61,62)$. Although a mucosal response in the intestine after subcutaneous immunization with FhKTM/CpG-ODN/Coa-ASC16 might seem surprising, recent findings have shown that parenteral immunization can generate a potent IgA response in mucosal tissues $(63,64)$. This fact could be explained in two hypothetical ways: in one of them, the antigen is captured by APC in the injection site and then transported to mucosal-associated lymphoid tissues (MALT) for antigen presentation. In the other, the antigen can be presented peripherally to naive $\mathrm{T}$ cells and $\mathrm{B}$ cells which are in turn home to mucosal tissues. The high levels of IFN- $\gamma$ and IL17A observed in inguinal lymph nodes after immunization with FhKTM/CpG-ODN/Coa-ASC16 (data not shown) suggest that the APC carrying the antigen might spread to the draining peripheral lymph nodes, either prior to or simultaneously with the antigen presentation to lymphocytes in the MALT. One limitation in this type of approach to studying protective immunity is the difficulty to decide whether protection comes from mucosal or systemic immunity, suggesting that induction of mucosal immunity by parenteral injection is an important issue for vaccine design. Finally, we believe that the CpG-ODN/CoaASC16 platform might allow FhKTM-long term release. CoaASC16 nanostructure have a certain rigidity, which can either modulate the release of molecule/s into the biological medium or provide stability to loaded molecules (65). Previously, it has

\section{REFERENCES}

1. Molina-Hernandez V, Mulcahy G, Perez J, Martinez-Moreno A, Donnelly S, O'Neill SM, et al. Fasciola hepatica vaccine: we may not be there been reported by in vitro approaches that Coa-ASC16 generates a sustained release of both OVA and CpG-ODN (27). In addition, Coa-ASC16 could exert a protective effect, avoiding FhKTM antigen protease degradation. This strategy may work in vivo as a depot effect, which often makes it possible to reduce the dose and/or the number of immunizations required for an optimal response.

The precise protective immunity mechanism as induced by FhKTM remains to be investigated. However, our data highlight the importance of designing vaccines that induce a potent response in mucosa and systemic levels capable of preventing the parasite from reaching the liver. Given the high levels of protection shown in mice susceptible to the infection, our next step is the validation of this vaccine system to the natural hosts of the infection, such as sheep, upon which our regional livestock economy is based.

\section{DATA AVAILABILITY STATEMENT}

The raw data supporting the conclusions of this article will be made available by the authors, without undue reservation.

\section{AUTHOR CONTRIBUTIONS}

LC and LS conceived of and designed the experiments and wrote the paper. LS, DC, PR, and MS performed the experiments. LC, LS, PR, LSC, CM, and BM analyzed the data. BM, SP, and DA conceived, developed, and tested the adjuvant capacity of CpGODN/Coa-ASC16. RS and CP produced the metacercariae. LC, CM, LSC, and PR contributed reagents, materials, and analysis tools. PR, LSC, BM, and CM revised the manuscript. All authors contributed to the article and approved the submitted version.

\section{FUNDING}

This work was supported by grants from the Consejo Nacional de Investigaciones Científicas y Técnicas of Argentina (CONICET) P 2015-2017A-A GI, 112201501002 60CO, Agencia Nacional de Promoción Científica y Técnica (PICT-2015-1179 and 2488), and Secretaría de Ciencia y Técnica-Universidad Nacional de Córdoba (grants to LC and CM).

\section{ACKNOWLEDGMENTS}

The authors thank Laura Gatica, Gabriela Furlan, Alejandra Romero, Pilar Crespo, Victoria Blanco, Diego Lutti, Fabricio Navarro, and Paula Abadie for their skillful technical assistance. The authors thank Marcelo Yantorno for English revision of the manuscript. LC, CM, PR, BM, SP, DA, RS, and LSC are members of the Scientific Career of CONICET.

2. Mas-Coma S, Valero MA, Bargues MD. Chapter 2. Fasciola, lymnaeids and human fascioliasis, with a global overview on disease transmission, 
epidemiology, evolutionary genetics, molecular epidemiology and control. Adv Parasitol. (2009) 69:41-46. doi: 10.1016/S0065-308X(09)69002-3

3. Vazquez AA, de Vargas M, Alba A, Sanchez J, Alda P, Sabourin $\mathrm{E}$, et al. Reviewing fasciola hepatica transmission in the west Indies and novel perceptions from experimental infections of sympatric vs. allopatric snail/fluke combinations. Vet Parasitol. (2019) 275:108955. doi: 10.1016/j.vetpar.2019.108955

4. Fairweather I, Brennan GP, Hanna REB, Robinson MW, Skuce PJ. Drug resistance in liver flukes. Int J Parasitol Drugs Drug Resist. (2020) 12:39-59. doi: 10.1016/j.ijpddr.2019.11.003

5. Kelley JM, Elliott TP, Beddoe T, Anderson G, Skuce P, Spithill TW. Current threat of triclabendazole resistance in fasciola hepatica. Trends Parasitol. (2016) 32:458-69. doi: 10.1016/j.pt.2016. 03.002

6. Falcon C, Carranza F, Martinez FF, Knubel CP, Masih DT, Motran CC, et al. Excretory-secretory products (ESP) from fasciola hepatica induce tolerogenic properties in myeloid dendritic cells. Vet Immunol Immunopathol. (2010) 137:36-46. doi: 10.1016/j.vetimm.2010.04.007

7. Hamilton CM, Dowling DJ, Loscher CE, Morphew RM, Brophy PM, O'Neill SM. The Fasciola hepatica tegumental antigen suppresses dendritic cell maturation and function. Infect Immun. (2009) 77:2488-98. doi: 10.1128/IAI.00919-08

8. Ravida A, Cwiklinski K, Aldridge AM, Clarke P, Thompson R, Gerlach JQ, et al. Fasciola hepatica surface tegument: glycoproteins at the interface of parasite and host. Mol Cell Proteomics. (2016) 15:3139-53. doi: 10.1074/mcp.M116.059774

9. Adams PN, Aldridge A, Vukman KV, Donnelly S, O'Neill SM. Fasciola hepatica tegumental antigens indirectly induce an M2 macrophage-like phenotype in vivo. Parasite Immunol. (2014) 36:531-9. doi: $10.1111 /$ pim. 12127

10. Vukman KV, Adams PN, O’Neill SM. Fasciola hepatica tegumental coat antigen suppresses MAPK signalling in dendritic cells and upregulates the expression of SOCS3. Parasite Immunol. (2013) 35:234-8. doi: 10.1111/pim.12033

11. Donnelly S, O'Neill SM, Sekiya M, Mulcahy G, Dalton JP. Thioredoxin peroxidase secreted by fasciola hepatica induces the alternative activation of macrophages. Infect Immun. (2005) 73:166-73. doi: 10.1128/IAI.73.1.166-173.2005

12. Donnelly S, Stack CM, O'Neill SM, Sayed AA, Williams DL, Dalton JP. Helminth 2-Cys peroxiredoxin drives Th2 responses through a mechanism involving alternatively activated macrophages. FASEB J. (2008) 22:4022-32. doi: 10.1096/fj.08-106278

13. Pacheco IL, Abril N, Zafra R, Molina-Hernandez V, MoralesPrieto N, Bautista MJ, et al. Fasciola hepatica induces Foxp3 $\mathrm{T}$ cell, proinflammatory and regulatory cytokine overexpression in liver from infected sheep during early stages of infection. Vet Res. (2018) 49:56. doi: 10.1186/s13567-018-0550-x

14. Toet H, Piedrafita DM, Spithill TW. Liver fluke vaccines in ruminants: strategies, progress and future opportunities. Int J Parasitol. (2014) 44:915-27. doi: 10.1016/j.ijpara.2014.07.011

15. Spithill TW, Carmona C, Piedrafita D, Smooker PM. Prospects for immunoprophylaxis against fasciola hepatica (Liver Fluke). In: Caffrey CR, editor. Parasitic Helminths: Targets, Screens, Drugs and Vaccines. doi: 10.1002/9783527652969.ch28

16. Beesley NJ, Caminade C, Charlier J, Flynn RJ, Hodgkinson JE, MartinezMoreno A, et al. Fasciola and fasciolosis in ruminants in Europe: identifying research needs. Transbound Emerg Dis. (2018) 65(Suppl. 1):199-216. doi: 10.1111/tbed.12682

17. Carmona C, Tort JF. Fasciolosis in South America: epidemiology and control challenges. J Helminthol. (2017) 91:99-109. doi: 10.1017/S0022149X16000560

18. Piedrafita D, Estuningsih E, Pleasance J, Prowse R, Raadsma HW, Meeusen EN, et al. Peritoneal lavage cells of indonesian thin-tail sheep mediate antibody-dependent superoxide radical cytotoxicity in vitro against newly excysted juvenile fasciola gigantica but not juvenile fasciola hepatica. Infect Immun. (2007) 75:1954-63. doi: 10.1128/IAI.01034-06

19. Falcon CR, Carranza FA, Aoki P, Motran CC, Cervi L. Adoptive transfer of dendritic cells pulsed with fasciola hepatica antigens and lipopolysaccharides confers protection against fasciolosis in mice. J Infect Dis. (2012) 205:506-14 doi: 10.1093/infdis/jir606

20. Cervi L, Borgonovo J, Egea M, Chiapello L, Masih D. Immunization of rats against fasciola hepatica using crude antigens conjugated with freund's adjuvant or oligodeoxynucleotides. Vet Immunol Immunopathol. (2004) 97:97-104. doi: 10.1016/j.vetimm.2003.08.015

21. Garza-Cuartero L, Geurden T, Mahan SM, Hardham JM, Dalton JP, Mulcahy G. Antibody recognition of cathepsin L1-derived peptides in fasciola hepatica-infected and/or vaccinated cattle and identification of protective linear B-cell epitopes. Vaccine. (2018) 36:958-68. doi: 10.1016/j.vaccine.2018. 01.020

22. Rojas-Caraballo J, López-Abán J, Pérez del Villar L, Vizcaíno C, Vicente $\mathrm{B}$, Fernández-Soto $\mathrm{P}$, et al. In vitro and in vivo studies for assessing the immune response and protection-inducing ability conferred by fasciola hepatica-derived synthetic peptides containing B- and Tcell epitopes. PLoS ONE. (2014) 9:e105323. doi: 10.1371/journal.pone. 0105323

23. Cwiklinski K, Donnelly S, Drysdale O, Jewhurst H, Smith D, De Marco Verissimo C, et al. The cathepsin-like cysteine peptidases of trematodes of the genus fasciola. Adv Parasitol. (2019) 104:113-64. doi: 10.1016/bs.apar.2019.01.001

24. Robinson MW, Menon R, Donnelly SM, Dalton JP, Ranganathan S. An integrated transcriptomics and proteomics analysis of the secretome of the helminth pathogen fasciola hepatica: proteins associated with invasion and infection of the mammalian host. Mol Cell Proteomics. (2009) 8:1891-907. doi: 10.1074/mcp.M900045-MCP200

25. Smith D, Tikhonova IG, Jewhurst HL, Drysdale OC, Dvorak J, Robinson MW, et al. Unexpected activity of a novel kunitz-type inhibitor: inhibition of cysteine proteases but not serine proteases. J Biol Chem. (2016) 291:19220-34. doi: $10.1074 /$ jbc.M116.724344

26. Karch CP, Burkhard P. Vaccine technologies: from whole organisms to rationally designed protein assemblies. Biochem Pharmacol. (2016) 120:1-14. doi: 10.1016/j.bcp.2016.05.001

27. Sanchez Vallecillo MF, Ullio Gamboa GV, Palma SD, Harman MF, Chiodetti AL, Moron G, et al. Adjuvant activity of CpG-ODN formulated as a liquid crystal. Biomaterials. (2014) 35:2529-42. doi: 10.1016/j.biomaterials.2013.12.002

28. Chiodetti AL, Sanchez Vallecillo MF, Dolina JS, Crespo MI, Marin C, Schoenberger SP, et al. Class-B CpG-ODN formulated with a nanostructure induces type I interferons-dependent and $\mathrm{CD}^{+}{ }^{+} \mathrm{T}$ cell-independent $\mathrm{CD} 8^{+}$ T-cell response against unconjugated protein antigen. Front Immunol. (2018) 9:2319. doi: 10.3389/fimmu.2018.02319

29. Bozas SE, Panaccio M, Creaney J, Dosen M, Parsons JC, Vlasuk $\mathrm{GV}$, et al. Characterisation of a novel kunitz-type molecule from the trematode fasciola hepatica. Mol Biochem Parasitol. (1995) 74:19-29. doi: 10.1016/0166-6851(95)02478-6

30. Gladiator A, LeibundGut-Landmann S. Innate lymphoid cells: new players in IL-17-mediated antifungal immunity. PLoS Pathog. (2013) 9:e1003763. doi: 10.1371/journal.ppat.1003763

31. Changklungmoa N, Phoinok N, Yencham C, Sobhon P, Kueakhai P. Vaccine potential of recombinant cathepsinL1G against fasciola gigantica in mice. Vet Parasitol. (2016) 226:124-31. doi: 10.1016/j.vetpar.2016.07.009

32. Chen CC, Louie S, McCormick B, Walker WA, Shi HN. Concurrent infection with an intestinal helminth parasite impairs host resistance to enteric citrobacter rodentium and enhances citrobacter-induced colitis in mice. Infect Immun. (2005) 73:5468-81. doi: 10.1128/IAI.73.9.5468-5481.2005

33. Pasquevich KA, Ibanez AE, Coria LM, Garcia Samartino C, Estein SM, Zwerdling A, et al. An oral vaccine based on U-Omp19 induces protection against $B$. Abortus mucosal challenge by inducing an adaptive IL-17 immune response in mice. PLoS ONE. (2011) 6:e16203. doi: 10.1371/journal.pone.0016203

34. Mulcahy G, O'Connor F, McGonigle S, Dowd A, Clery DG, Andrews SJ, et al. Correlation of specific antibody titre and avidity with protection in cattle immunized against fasciola hepatica. Vaccine. (1998) 16:932-9. doi: 10.1016/S0264-410X(97)00289-2

35. Wesolowska A, Basalaj K, Norbury LJ, Sielicka A, Wedrychowicz H, Zawistowska-Deniziak A. Vaccination against fasciola hepatica using 
cathepsin L3 and B3 proteases delivered alone or in combination. Vet Parasitol. (2018) 250:15-21. doi: 10.1016/j.vetpar.2017.12.007

36. Stempin CC, Motran CC, Aoki MP, Falcon CR, Cerban FM, Cervi L. PD-L2 negatively regulates Th1-mediated immunopathology during Fasciola hepatica infection. Oncotarget. (2016) 7:77721-31. doi: 10.18632/oncotarget.12790

37. Milpied PJ, McHeyzer-Williams MG. High-affinity IgA needs TH17 cell functional plasticity. Nat Immunol. (2013) 14:313-5. doi: 10.1038/ni.2567

38. Dann SM, Manthey CF, Le C, Miyamoto Y, Gima L, Abrahim A, et al. IL$17 \mathrm{~A}$ promotes protective IgA responses and expression of other potential effectors against the lumen-dwelling enteric parasite giardia. Exp Parasitol. (2015) 156:68-78. doi: 10.1016/j.exppara.2015.06.003

39. Kataoka H, Ohara M, Shibui K, Sato M, Suzuki T, Amemiya N, et al. Overweight and obesity accelerate the progression of IgA nephropathy: prognostic utility of a combination of BMI and histopathological parameters. Clin Exp Nephrol. (2012) 16:706-12. doi: 10.1007/s10157-012-0613-7

40. Fracasso M, Da Silva AS, Baldissera MD, Bottari NB, Gabriel ME, Piva MM, et al. Activities of ectonucleotidases and adenosine deaminase in platelets of cattle experimentally infected by fasciola hepatica. Exp Parasitol. (2017) 176:16-20. doi: 10.1016/j.exppara.2017.02.014

41. Nascimento MS, Carregaro V, Lima-Junior DS, Costa DL, Ryffel B, Duthie MS, et al. Interleukin $17 \mathrm{~A}$ acts synergistically with interferon gamma to promote protection against leishmania infantum infection. J Infect Dis. (2015) 211:1015-26. doi: 10.1093/infdis/jiu531

42. Sharkey RM, Rossi EA, McBride WJ, Chang CH, Goldenberg DM. Recombinant bispecific monoclonal antibodies prepared by the dock-andlock strategy for pretargeted radioimmunotherapy. Semin Nucl Med. (2010) 40:190-203. doi: 10.1053/j.semnuclmed.2009.12.002

43. Norbury LJ, Basalaj K, Zawistowska-Deniziak A, Sielicka A, Wilkowski $\mathrm{P}$, Wesolowska $\mathrm{A}$, et al. Intranasal delivery of a formulation containing stage-specific recombinant proteins of fasciola hepatica cathepsin L5 and cathepsin B2 triggers an anti-fecundity effect and an adjuvant-mediated reduction in fluke burden in sheep. Vet Parasitol. (2018) 258:14-23. doi: 10.1016/j.vetpar.2018.05.008

44. Mendes RE, Perez-Ecija RA, Zafra R, Buffoni L, Martinez-Moreno A, Dalton JP, et al. Evaluation of hepatic changes and local and systemic immune responses in goats immunized with recombinant peroxiredoxin (Prx) and challenged with fasciola hepatica. Vaccine. (2010) 28:2832-40. doi: $10.1016 /$ j.vaccine.2010.01.055

45. Espino AM, Morales A, Delgado B, Rivera FM, Figueroa O, Suarez E. Partial immunity to fasciola hepatica in mice after vaccination with FhSAP2 delivered as recombinant protein or DNA construct. Ethn Dis. (2010) 20(1 Suppl. 1):S1$17-23$.

46. Lopez-Aban J, Casanueva P, Nogal J, Arias M, Morrondo P, Diez-Banos P, et al. Progress in the development of fasciola hepatica vaccine using recombinant fatty acid binding protein with the adjuvant adaptation system ADAD. Vet Parasitol. (2007) 145:287-96. doi: 10.1016/j.vetpar.2006.12.017

47. Roach TI, Else KJ, Wakelin D, McLaren DJ, Grencis RK. Trichuris muris: antigen recognition and transfer of immunity in mice by IgA monoclonal antibodies. Parasite Immunol. (1991) 13:1-12. doi: 10.1111/j.1365-3024.1991.tb00258.x

48. McSorley HJ, Hewitson JP, Maizels RM. Immunomodulation by helminth parasites: defining mechanisms and mediators. Int J Parasitol. (2013) 43:30110. doi: 10.1016/j.ijpara.2012.11.011

49. Esser-von Bieren J, Mosconi I, Guiet R, Piersgilli A, Volpe B, Chen F, et al. Antibodies trap tissue migrating helminth larvae and prevent tissue damage by driving IL-4Ralpha-independent alternative differentiation of macrophages. PLoS Pathog. (2013) 9:e1003771. doi: 10.1371/journal.ppat.1003771

50. McCoy KD, Stoel M, Stettler R, Merky P, Fink K, Senn BM, et al. Polyclonal and specific antibodies mediate protective immunity against enteric helminth infection. Cell Host Microbe. (2008) 4:362-73. doi: 10.1016/j.chom.2008.08.014

51. Sorobetea D, Svensson-Frej M, Grencis R. Immunity to gastrointestinal nematode infections. Mucosal Immunol. (2018) 11:304-15. doi: $10.1038 / \mathrm{mi} .2017 .113$

52. Piedrafita D, Parsons JC, Sandeman RM, Wood PR, Estuningsih SE, Partoutomo S, et al. Antibody-dependent cell-mediated cytotoxicity to newly excysted juvenile fasciola hepatica in vitro is mediated by reactive nitrogen intermediates. Parasite Immunol. (2001) 23:473-82. doi: 10.1046/j.1365-3024.2001.00404.x

53. Noya V, Brossard N, Berasain P, Rodriguez E, Chiale C, Mazal D, et al. A mucin-like peptide from fasciola hepatica induces parasitespecific Th1-type cell immunity. Parasitol Res. (2016) 115:1053-63. doi: 10.1007/s00436-015-4834-z

54. Hirota K, Turner JE, Villa M, Duarte JH, Demengeot J, Steinmetz OM, et al. Plasticity of Th17 cells in peyer's patches is responsible for the induction of T cell-dependent IgA responses. Nat Immunol. (2013) 14:372-9. doi: $10.1038 /$ ni. 2552

55. Das S, Khader S. Yin and yang of interleukin-17 in host immunity to infection. F1000Res. (2017) 6:741. doi: 10.12688/f1000research.10862.1

56. Trautwein-Weidner K, Gladiator A, Nur S, Diethelm P, LeibundGutLandmann S. IL-17-mediated antifungal defense in the oral mucosa is independent of neutrophils. Mucosal Immunol. (2015) 8:221-31. doi: $10.1038 / \mathrm{mi} .2014 .57$

57. Burstein VL, Guasconi L, Beccacece I, Theumer MG, Mena C, Prinz I, et al. IL17-mediated immunity controls skin infection and Thelper 1 response during experimental microsporum canis dermatophytosis. J Invest Dermatol. (2018) 138:1744-53. doi: 10.1016/j.jid.2018.02.042

58. Chen K, Eddens T, Trevejo-Nunez G, Way EE, Elsegeiny W, Ricks DM, et al. IL-17 Receptor signaling in the lung epithelium is required for mucosal chemokine gradients and pulmonary host defense against $\mathrm{K}$. pneumoniae. Cell Host Microbe. (2016) 20:596-605. doi: 10.1016/j.chom.2016. 10.003

59. Ross PJ, Sutton CE, Higgins S, Allen AC, Walsh K, Misiak A, et al. Relative contribution of Th1 and Th17 cells in adaptive immunity to bordetella pertussis: towards the rational design of an improved acellular pertussis vaccine. PLoS Pathog. (2013) 9:e1003264. doi: 10.1371/journal.ppat. 1003264

60. Amit A, Vijayamahantesh Dikhit MR, Singh AK, Kumar V, Suman SS, Singh A, et al. Immunization with leishmania donovani protein disulfide isomerase DNA construct induces Th1 and Th17 dependent immune response and protection against experimental visceral leishmaniasis in Balb/c mice. Mol Immunol. (2017) 82:104-13. doi: 10.1016/j.molimm.2016.12.022

61. Gao Q, Liu Y, Wu Y, Zhao Q, Wang L, Gao S, et al. IL-17 intensifies IFN-gamma-induced NOS2 upregulation in RAW 264.7 cells by further activating STAT1 and NF-kappaB. Int J Mol Med. (2016) 37:347-58. doi: $10.3892 / \mathrm{ijmm} .2015 .2433$

62. Lin Y, Ritchea S, Logar A, Slight S, Messmer M, Rangel-Moreno J, et al. Interleukin-17 is required for T helper 1 cell immunity and host resistance to the intracellular pathogen francisella tularensis. Immunity. (2009) 31:799-810. doi: 10.1016/j.immuni.2009.08.025

63. Su F, Patel GB, Hu S, Chen W. Induction of mucosal immunity through systemic immunization: phantom or reality? Hum Vaccin Immunother. (2016) 12:1070-9. doi: 10.1080/21645515.2015.11 14195

64. Clements JD, Freytag LC. Parenteral vaccination can be an effective means of inducing protective mucosal responses. Clin Vaccine Immunol. (2016) 23:438-41. doi: 10.1128/CVI.00214-16

65. Palma S, Manzo R, Lo Nostro P, Allemandi D. Nanostructures from alkyl vitamin C derivatives (ASCn): properties and potential platform for drug delivery. Int J Pharm. (2007) 345:26-34. doi: 10.1016/j.ijpharm.2007. 09.014

Conflict of Interest: The authors declare that the research was conducted in the absence of any commercial or financial relationships that could be construed as a potential conflict of interest.

Copyright $\odot 2020$ Silvane, Celias, Romagnoli, Maletto, Sanchez Vallecillo, Chiapello, Palma, Allemandi, Sanabria, Pruzzo, Motrán and Cervi. This is an open-access article distributed under the terms of the Creative Commons Attribution License (CC $B Y)$. The use, distribution or reproduction in other forums is permitted, provided the original author(s) and the copyright owner(s) are credited and that the original publication in this journal is cited, in accordance with accepted academic practice. No use, distribution or reproduction is permitted which does not comply with these terms. 